Supporting information

\title{
Absorption, Biokinetics, and Metabolism of the Dopamine D2 Receptor Agonist Hordenine ( $N, N$ - Dimethyltyramine) after Beer Consumption in Humans
}

Thomas Sommer, ${ }^{+, \neq}$Thomas Göen, ${ }^{\S}$ Nadja Budnik, ${ }^{\S}$ and Monika Pischetsrieder ${ }^{+*}$

${ }^{+}$Department of Chemistry and Pharmacy, Food Chemistry, Friedrich-Alexander-Universität ErlangenNürnberg, Nikolaus-Fiebiger-Str. 10, 91058 Erlangen, Germany

${ }^{\ddagger}$ Department of Chemistry and Pharmacy, Computer Chemistry Center, Friedrich-Alexander-Universität Erlangen-Nürnberg, Nägelsbachstr. 25, 91052 Erlangen, Germany

$\S$ Institute and Outpatient Clinic of Occupational, Social and Environmental Medicine, FriedrichAlexander-Universität Erlangen-Nürnberg, Schillerstr. 25/29, 91054 Erlangen, Germany

*Correspondence to M.P., Chair of Food Chemistry, Friedrich-Alexander-Universität Erlangen-Nürnberg, Nikolaus-Fiebiger-Str. 10, 91058 Erlangen, Germany; Fax: +49-9131-8522131; Phone: + 49-91318565592; E-Mail: monika.pischetsrieder@fau.de.

\section{Contents:}

Table S1 Calibration curves for hordenine in standard solution and human plasma

Table S2 Validation parameters for the quantification of hordenine

Figure S1 Mass spectrometry chromatograms of blank and spiked plasma 
Table S1: Calibration curves for the determination of hordenine in standard solution ( $0.1 \%$ formic acid) and in human plasma matrix. The ratio of analyte to internal hordenine-d6 standard was plotted versus the concentration of the analyte and linear regression analysis was performed. Due to a 1:3 dilution during sample preparation, the calibration range in human plasma is threefold the calibration range in $0.1 \%$ formic acid. The equations of the mean curves $(n=3)$ are shown.

\begin{tabular}{clll}
\hline & calibration range & linear regression & $\mathrm{R}^{2}$ \\
\hline $\begin{array}{c}\text { in } \mathbf{0 . 1 \%} \text { formic acid } \\
\text { lower section } \\
\begin{array}{c}\text { upper section } \\
\text { in human plasma }\end{array}\end{array}$ & $0.15-4.5 \mathrm{nM}$ & $0.160556 \mathrm{x}-0.000497$ & 0.9996 \\
$\begin{array}{c}\text { lower section } \\
\text { upper section } \\
\text { for calculation of } \\
\text { LOD and LOQ }\end{array}$ & $0.45-13.6 \mathrm{nM}$ & $0.148971 \mathrm{x}+0.040116$ & 0.9999 \\
\hline
\end{tabular}

Table S2: Validation parameters for the quantification of hordenine in human plasma. For the determination of precision, accuracy, and process recoveries, the QC samples were used ( $n=4$, on three different days, in total $n=12$ determinations). Total intraday precision is expressed as mean value of three days. Matrix effects were determined once at each validation day ( $n=3$ determinations in total).

\begin{tabular}{|c|c|c|c|c|c|c|c|}
\hline & \multicolumn{2}{|l|}{$\begin{array}{l}\text { precision } \\
(\% \mathrm{CV})\end{array}$} & \multirow[t]{2}{*}{$\begin{array}{l}\text { accuracy } \\
(\%)\end{array}$} & \multicolumn{2}{|c|}{$\begin{array}{l}\text { matrix effects } \\
(\% \pm \text { SD) }\end{array}$} & \multicolumn{2}{|c|}{$\begin{array}{l}\text { process recoveries } \\
(\% \pm S D)\end{array}$} \\
\hline & intraday & interday & & hordenine & IS ${ }^{b}$ & hordenine & IS b \\
\hline $\begin{array}{l}\text { QClow } \\
(0.61 \mathrm{nM})\end{array}$ & $4.2^{\mathrm{a}}$ & $7.8^{\mathrm{a}}$ & $104.4^{\mathrm{a}}$ & $97.2 \pm 2.2$ & $100.4 \pm 4.2$ & $90.5 \pm 2.6^{a}$ & $92.6 \pm 4.0^{a}$ \\
\hline $\begin{array}{l}\mathrm{QC}_{\text {mid }} \\
(12.1 \mathrm{nM})\end{array}$ & 2.5 & 2.9 & 99.7 & $102.3 \pm 7.0$ & $101.0 \pm 3.7$ & $92.2 \pm 5.2$ & $94.2 \pm 5.0$ \\
\hline $\begin{array}{l}\text { QChigh } \\
(121.0 \mathrm{nM})\end{array}$ & 1.9 & 3.8 & 105.3 & $100.3 \pm 4.0$ & $99.1 \pm 0.4$ & $92.4 \pm 4.3$ & $92.1 \pm 4.2$ \\
\hline
\end{tabular}



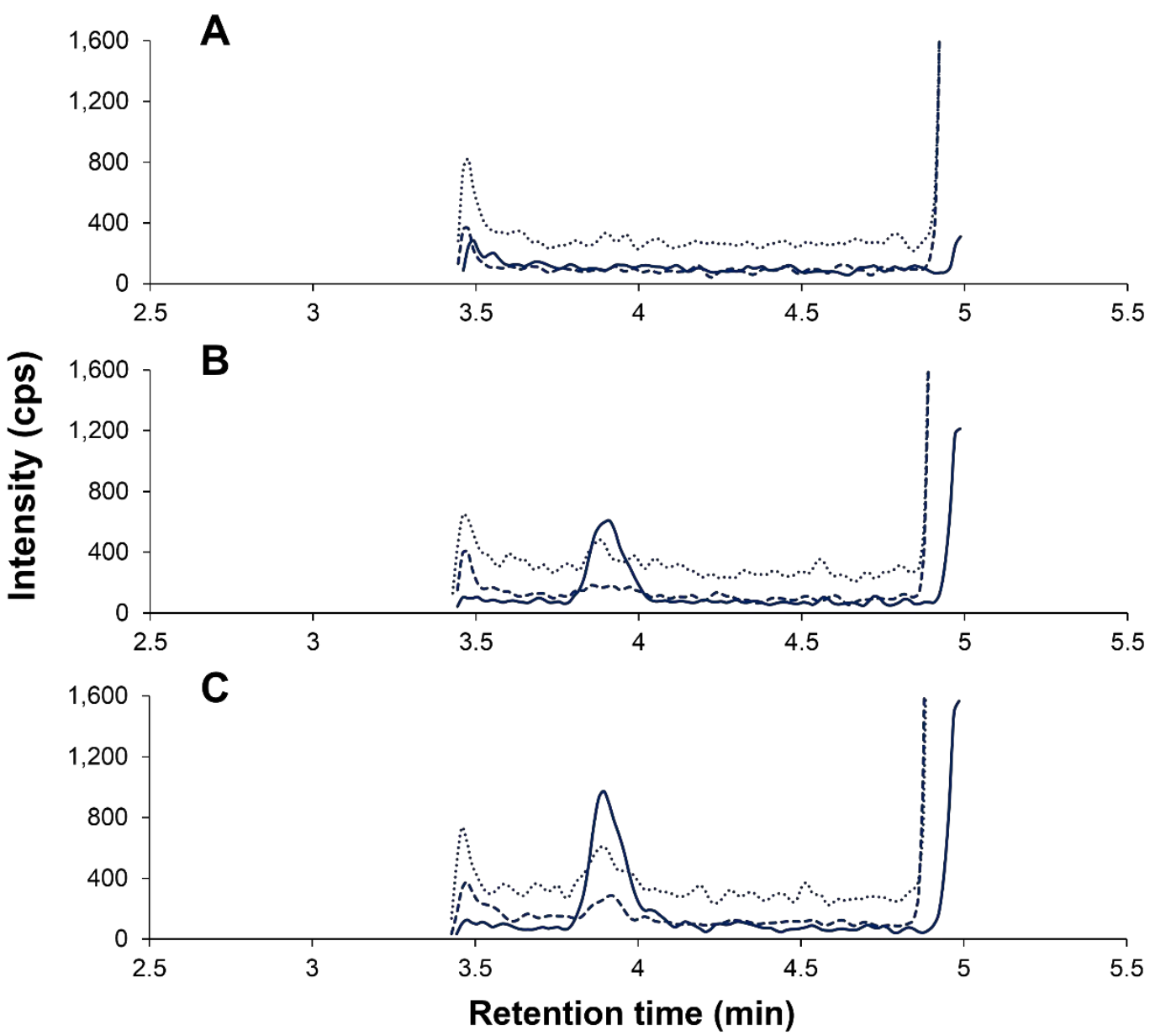

Figure S1: UHPLC-ESI-MS/MS-sMRM chromatograms of (A) blank plasma, (B) blank plasma spiked with $0.18 \mathrm{nM}(0.030 \mathrm{ng} / \mathrm{mL})$ hordenine (LOD), and (C) blank plasma spiked with $0.33 \mathrm{nM}(0.055 \mathrm{ng} / \mathrm{mL})$ hordenine (LOQ). The solid lines represent the quantifier $(\mathrm{m} / z$ 166.1 $\rightarrow 121.0)$, the dashed lines the qualifier $1(\mathrm{~m} / z 166.1 \rightarrow 103.0)$, and the dotted lines the qualifier 2 transition $(\mathrm{m} / z 166.1 \rightarrow 77.0)$. The transitions were monitored between minutes 3.4 and 5.0 of the UHPLC run. The retention time of hordenine was about $4 \mathrm{~min}$. The peak discernable starting from minute 4.9 corresponds to endogenous phenylalanine. 